\title{
Corrected transposition of great vessels and Ebstein's anomaly of tricuspid valve Echocardiographic findings
}

\author{
JAMES G. HENRY, SEYMOUR GORDON, AND GERALD C. TIMMIS \\ From the Division of Cardiovascular Diseases, William Beaumont Hospital, Royal Oak, Michigan, USA
}

SUMMARY A case is reported concerning echocardiographic findings in a patient with congenital corrected transposition of the great vessels and Ebstein's anomaly of the tricuspid valve. This presented an unusual opportunity to study atrioventricular valve closure in a patient in whom the Ebstein's malformation involved the systemic atrioventricular valve. The mitral to tricuspid valve closure interval was 68 milliseconds and represented significant delay in tricuspid valve closure. This closure interval is similar to closure intervals previously reported for patients with Ebstein's anomaly without ventricular inversion.

Recent echocardiographic studies have detailed the timing of atrioventricular valve closure in Ebstein's anomaly of the tricuspid valve (Kotler and Tabatznik, 1971; Lundström, 1973; Farooki et al., 1976; Milner et al., 1976). These studies indicate the diagnostic value of delayed tricuspid closure. The mechanism of delayed tricuspid closure is speculative (Lundström, 1973; Milner et al., 1976). The patient described here provided an opportunity to study atrioventricular valve closure in ventricular inversion (congenital corrected transposition of the great vessels) and Ebstein's malformation of the systemic atrioventricular valve.

\section{Case report}

A 22-month-old girl was admitted for further cardiovascular diagnostic studies. A diagnosis of corrected transposition of the great vessels and regurgitation of the systemic atrioventricular valve had been made by cardiac catheterisation and angiocardiography at 3 weeks of age. In the ensuing 21 months, she showed slow growth and frequent respiratory infections. Re-evaluation at 22 months revealed a small, thin, acyanotic toddler in no distress. There was a hyperdynamic impulse in the left parasternal area. A pansystolic murmur was present at the lower left sternal border and apex. An apical mid-diastolic murmur was present. The second heart sound was single and accentuated. The liver was palpable $2 \mathrm{~cm}$ below the right costal margin.

An electrocardiogram revealed a $Q R S$ duration of $0.10 \mathrm{~s}$ (lead II). Slurring of the upstroke of the $R$ wave was present in leads I, V5, and V6.

Cardiac catheterisation (Table) disclosed moderate pulmonary arterial hypertension, raised pulmonary arterial wedge pressures, and a marginally significant increase in oxygen saturation between systemic venous and pulmonary arterial blood. Cineangiocardiography with selective opacification of systemic and pulmonary ventricles showed ventricular inversion and 1-transposition of the great vessels. Displacement of the tricuspid valve leaflets distally into the sinus of the right ventricle was noted (Fig. 1), producing an angiographic picture previously described in Ebstein's malformation of the tricuspid valve with ventricular inversion (Jaffee,

Table Catheterisation data

\begin{tabular}{lll}
\hline Site & $\begin{array}{l}\% \text { Oxygen } \\
\text { saturation }\end{array}$ & $\begin{array}{l}\text { Pressure }(\mathrm{mmHg}) \\
\text { systolic/diastolic }\end{array}$ \\
\hline Superior vena cava & 64 & \\
Inferior vena cava & 71 & $\mathrm{a}=6, \mathrm{v}=5$, mean $=3$ \\
Right atrium & 72 & $49 / 5$ \\
Left ventricle & 72 & $51 / 24$ mean $=36$ \\
Pulmonary artery & 72 & $\mathrm{a}=24, \mathrm{v}=24$, mean $=18$ \\
Pulmonary capillary & 98 & $78 / 6$ \\
Right ventricle & 96 & $79 / 53$ mean $=67$ \\
Aorta & 96 & \\
\hline
\end{tabular}




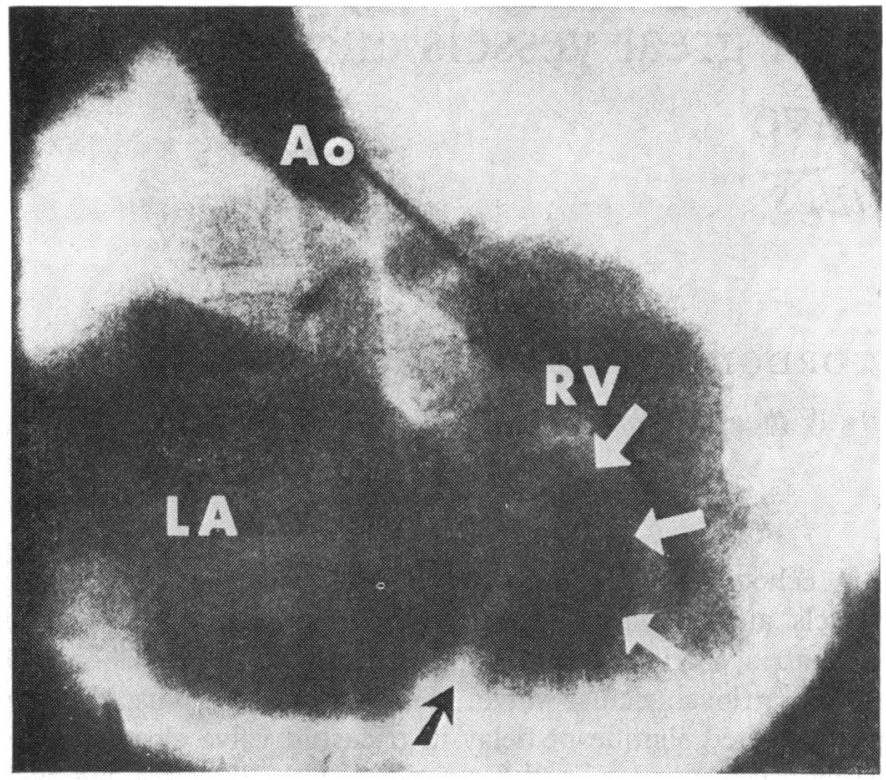

Fig. 1 Anteroposterior projection of systemic ventricular cineangiocardiogram. The ventricle is coarsely trabeculated and has an infundibulum separating the systemic atrioventricular valve from the aortic valve. The black arrow indicates the atrioventricular valve ring. The 3 white arrows indicate the displaced tricustid valve leaflet. Note distinct tricuspid regurgitation into the enlarged left atrium. Ao, aorta; $L A$, left atrium; $R V$, anatomical right ventricle.

1976). Pronounced tricuspid regurgitation was observed.

\section{ECHOCARDIOGRAPHIC TECHNIQUE AND RESULTS}

Echocardiographic recordings were performed with an Ekoline 20 ultrasonoscope and a $3.5 \mathrm{mHz}$ $1 / 4$ in transducer. A Cambridge strip chart recorder was used with $100 \mathrm{~mm}$ per second paper speed and 40 millisecond time lines.

The patient was examined in the supine position. The atrioventricular valves were identified by their relation to semilunar valves as described by Solinger et al. (1974). The posterior, left atrioventricular valve (tricuspid) was easily recorded in the 3rd and 4th intercostal spaces in a wide area from the left sternal border to the left midclavicular line. The anterior, right atrioventricular valve (mitral) was recorded only with medial angulation at the lower left sternal border.

Atrioventricular valve closure was identified by the point of coaptation of leaflets, or in the case of the tricuspid valve, that instant at which the two recorded leaflets sharply terminated their rapid approximation at the onset of systole ( $\mathrm{Mc}$ and $\mathrm{Tc}$ in Figs 2 and 3).

The interval between echocardiographic closure of the mitral and tricuspid valves (McTcI) was determined as follows:

The interval between the $Q$ wave of the electrocardiogram and mitral closure (Q-Mc) was determined by measurement of the interval to the nearest
5 milliseconds in 5 successive complexes with nearly identical $R R$ intervals and taking the average value. The interval between the $Q$ wave of the electrocardiogram and tricuspid closure (QTc) was determined in the same manner. McTcI was obtained by subtracting mean QMc from mean QTc. Heart rates during recordings for determination of QMc and QTc were similar, averaging 111 and 114 per minute, respectively.

The value obtained for McTcI was 68 milliseconds.

\section{Discussion}

The patient reported here has ventricular and atrioventricular valvular inversion. Thus the posterior, systemic atrioventricular valve is tricuspid. In addition, this posterior atrioventricular valve had the angiographic appearance of Ebstein's anomaly (Jaffee, 1976).

This case report is of value in two respects:

(1) It represents one of the few reported instances of echocardiographic closure of the anterior atrioventricular valve before closure of the posterior atrioventricular valve. To our knowledge this sequence of atrioventricular valve closure has been reported in only one normal subject (Milner et al., 1976) and has been reported as the usual finding in only one congenital cardiac defect, classical complete transposition of the great vessels (Milner et al., 1976). 


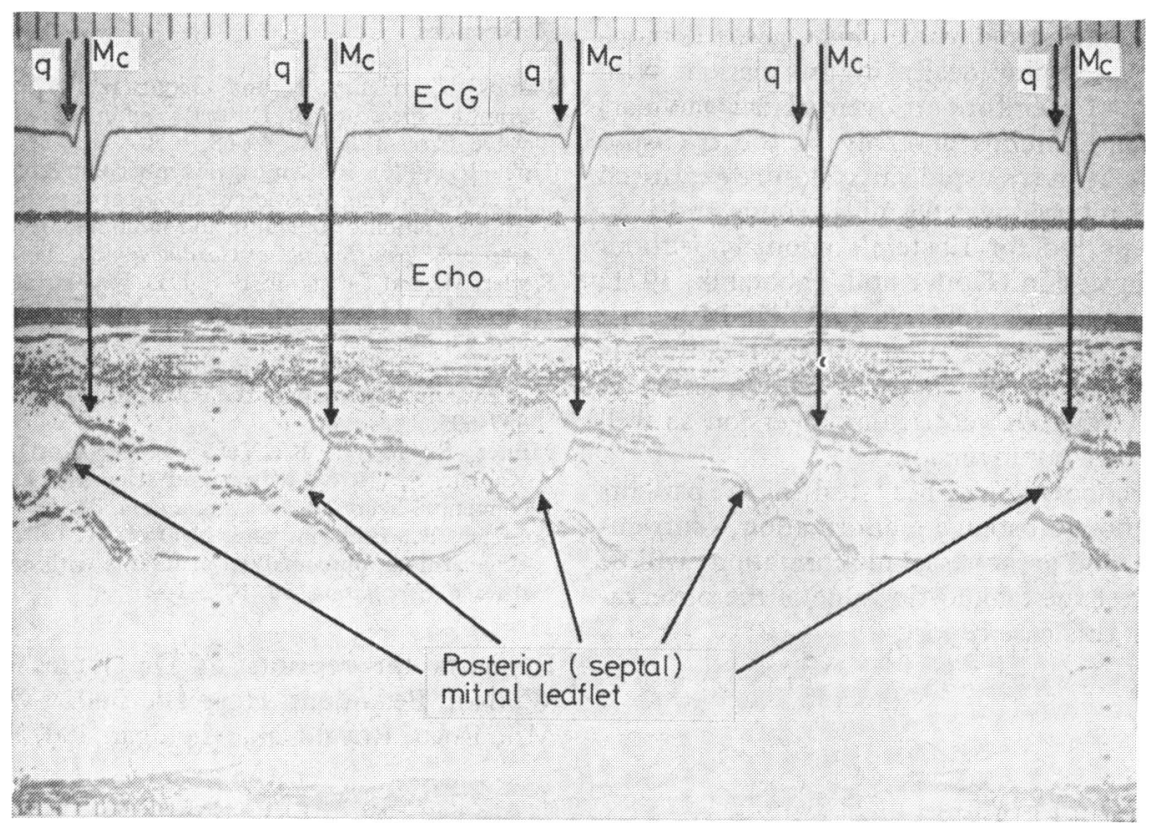

Fig. 2. Mitral valve echoes in corrected transposition of the great vessels. Echo, echocardiogram, ECG electrocardiogram; Mc, mitral closure point; $q$, initiation of $Q$ wave of the electrocardiogram.

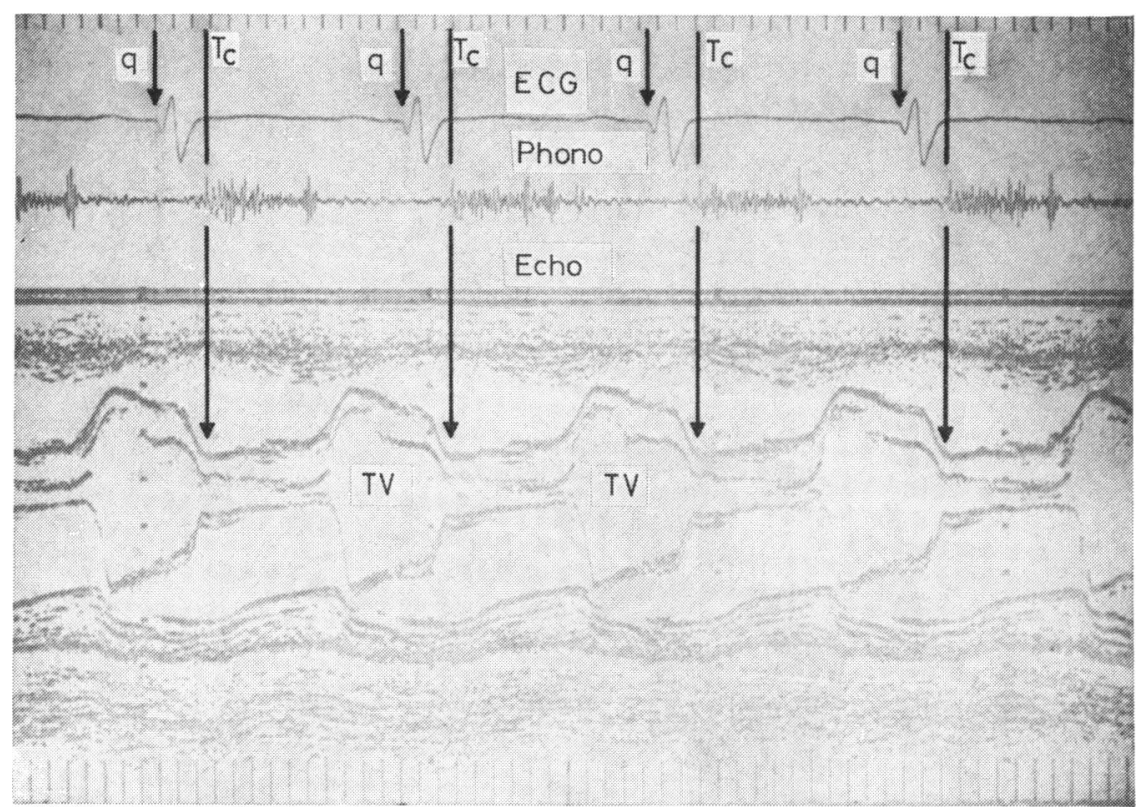

Fig. 3 Tricuspid valve echoes in corrected transposition of the great vessels. Echo, echocardiogram; ECG, electrocardiogram; Phono, phonocardiogram; $q$, initiation of $Q$ wave of the electrocardiogram; Tc, tricuspid closure point; TV, tricuspid valve echoes. 
(2) Delayed tricuspid valve closure was demonstrated echocardiographically in this patient with ventricular (and therefore atrioventricular valvular) inversion and Ebstein's anomaly of the tricuspid valve. The delay in tricuspid valve closure expressed as the McTc interval was 68 milliseconds and is in the range reported for Ebstein's anomaly without ventricular inversion (Kotler and Tabatznik, 1971; Lundström, 1973; Farooki et al., 1976; Milner et al., 1976). Thus delayed tricuspid valve closure is apparently a feature of Ebstein's malformation of the tricuspid valve in ventricular inversion as well as in ventricular noninversion.

Further echocardiographic studies in patients with and without Ebstein's malformation, ventricular inversion, and great vessel malformations will be required to test the diagnostic value of the observations cited in this case report.

\section{References}

Farooki, Z., Henry, J., and Green, E. (1976). Echocardiographic spectrum of Ebstein's anomaly of the tricuspid valve. Circulation, 53, 63-68.

Jaffee, R. (1976). Systemic atrioventricular valve regurgitation in corrected transposition of the great vessels. Angiographic differentiation of operable and nonoperable valve deformities. American fournal of Cardiology, 37, 395-402.

Kotler, M., and Tabatznik, B. (1971). Recognition of Ebstein's anomaly by ultrasound technique (abstract). Circulation, 43 and 44, Suppl. II, 34.

Lundström, N-R. (1973). Echocardiography in the diagnosis of Ebstein's anomaly of the tricuspid valve. Circulation, 47, 597-605.

Milner, S., Meyer, R., Venables, A., Korfhagen, J., and Kaplan, S. (1976). Mitral and tricuspid valve closure in congenital heart disease. Circulation, 53, 513-518.

Solinger, R., Elbl, F., and Minhas, K. (1974). Deductive echocardiographic analysis in infants with congenital heart disease. Circulation, 50, 1072-1096.

Requests for reprints to Dr James G. Henry, William Beaumont Hospital, 3601 W. Thirteen Mile Road, Royal Oak, Michigan 48072, USA. 